\title{
EXPERIMENTAL STUDY OF ANISOTROPY OF QUARTZ DISSOLUTION AND ITS ROLE IN FLUID MIGRATION IN ROCKS
}

\author{
Šárka BENEDOVÁ * and Jaromír LEICHMANN \\ Department of Geological Science, Faculty of Science, Masaryk University, Kotlářrká 2, Brno 61137, Czech Republic \\ *Corresponding author's e-mail: 67702@mail.muni.cz
}

\begin{tabular}{l} 
ARTICLE INFO \\
\hline Article history: \\
Received 4 May 2015 \\
Accepted 6 January 2016 \\
Available online 10. 2. 2016
\end{tabular}

Keywords:

Quartz dissolution

Crystal faces

Mechanical defects

Metasomatism

Alteration

\begin{abstract}
Quartz dissolution in hydrothermal-metasomatic processes is common feature in magmatic and metamorphic quartz rich rocks. This experimental work aims to compare the dissolution of individual quartz faces and to clarify the role of mechanical defects in quartz grain dissolution. Two types of experiments were made to define the dissolution anisotropy: hydrothermal experiments (quartz - distilled water) and chemical dissolution (quartz - $40 \%$ hydrofluoric acid).

Hydrothermal experiments using various types of quartz samples as well as chemical dissolution of quartz faces show that quartz dissolution is an anisotropic process. The solubility of rhombs is higher than that of prism faces. At lower temperatures the separated etch pits develop and with increasing temperature the etch pits start to link and the continuous striations (prisms) or overlapping arrows (rhombs) are observed. Such a surface structure may facilitate fluid migration through a solid rock. An experiment using a mechanically disrupted surface of the quartz crystal shows the decisive role of this defect on the dissolution. Fluid migration through rocks can then be strongly influenced for instance by brittle deformation, to which quartz with no cleavage is easily susceptible. Such defects additionally enhance fluid movement through rocks, which plays a decisive role during hydrothermal metasomatic quartz dissolution.
\end{abstract}

\section{INTRODUCTION}

Mineral dissolution is common in nature, reverse to mineral growth. Quartz as one of the major rockforming minerals is commonly subject to dissolution in all genetic rock types, i.e. magmatic (Petersson and Eliasson, 1997), metamorphic (Kříbek and Hájek, 2005) and sedimentary rocks (Gratz and Christie, 1993). Various aspects of this process such as the kinetics (Gratz et al., 1990; Liang and Readey, 1987) and thermodynamics (Shmulovich et al., 2001; Dolejs and Wagner, 2008) of dissolution have been studied by several authors.

This work describes quartz dissolution using hydrothermal experiments and chemical dissolution in order to constrain fluid migration during metasomatic proceses involving quartz dissolution. The extreme case of this process is episyenitization, a natural postmagmatic process resulting in episyenite formation (Hecht, 1999; Petersson and Eliasson, 1997). Episyenitization is a hydrothermal alteration process during which quartz is dissolved by fluid-rock interaction. It is commonly associated with other types of alteration, such as albitization, sepentinization etc., and with various types of mineralization, such as $U$ or Mo mineralization. Cathelineau (1986) stated the correlation between hydrothermal quartz dissolution in granites and sodium (albitization) or potassium (microclinization/sericitization) metasomatism. This correlation is also known from the Bohus granite in Sweden (Petersson and Eliasson, 1997).The formation of cavities which develop due to the dissolution of the original quartz results in increasing rock porosity, which facilitates fluid migration and creates space for the crystallization of new minerals which gradually fill the spaces.

These examples state that quartz dissolution creates space for new metasomatic alteration and increases the potential for rock alteration. Also Pielow (1998) concluded that the porosity of quartz caused by plagioclase alteration creates levels of higher permeability.

According to Cathelineu (1986), the pressure and temperature conditions during episyenitization range between $0.3-1.5 \mathrm{kbar}$ and $250-450{ }^{\circ} \mathrm{C}$. Metasomatizing fluids are aqueous with low salinity. Undersaturation of quartz in the fluids results from drastic temperature changes in the range 450 $350{ }^{\circ} \mathrm{C}$, and in most cases the $\mathrm{K}$ or $\mathrm{Na}$ metasomatism is controlled by the subsequent disequilibrium between fluids and host rocks (Cathelineau, 1986).

Mineral dissolution is usually perceived as an isotropic process dependent on temperature and pressure (Fig. 1). It is however well known that the character and rate of dissolution on different crystal 


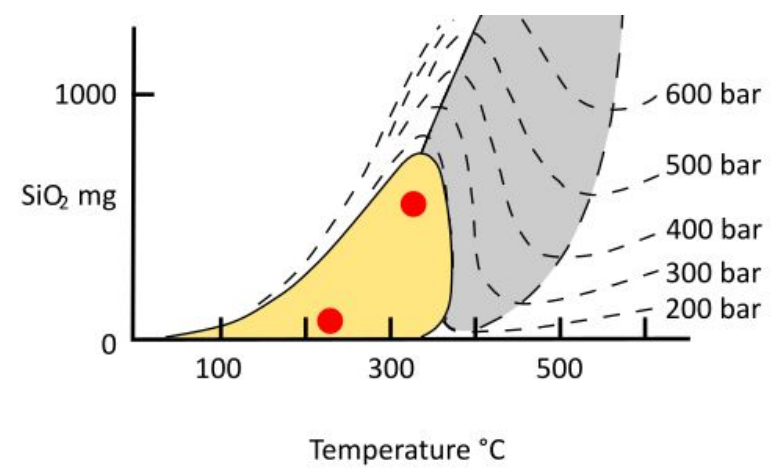

Fig. 1 Diagram showing quartz solubility in water. Simplified and adapted after Fournier (1985) and Petersson et al. (2012). The yellow field corresponds to the highest quartz solubility. In the grey field, the quartz solubility decreases at prograde conditions during constant pressure and quartz precipitates/crystallizes. The red dots show the conditions of the hydrothermal simulation experiments. Experiments with $\mathrm{HF}$ run in the ambient laboratory conditions: $\mathrm{T}=20^{\circ} \mathrm{C}$, atmospheric pressure.

faces varies. The dissolution rate is assumed similar for the same crystal face (for instance on all faces of a halite cube). Dissolution of crystalline minerals results in so-called etch pits, etch marks or etch hillocks, which reflect the crystal lattice. Both shape and location correspond to the symmetry of the etched surface.

According to Ježek (1932), the concentration of the etching fluid, temperature and duration of the experiment represent controlling factors during chemical etching. Different etch patterns may develop on the same face under different conditions and through the action of different agents. However, these corrosive forms always have the same symmetry typical for individual crystallographical plane. The effect of the internal structure of the crystal on the mode of dissolution is also documented by the etching of spheres, which have been cut from these minerals. Although there are no crystal faces on the surface of the spheres, contrasting types of etch patterns can be found. The use of a single solution type results not only in a different symmetry of etches on individual planes, but also in variable density, reflecting different dissolution intensities for different faces.

Lasaga and Blum (1986) studied the mechanism of development of etch pits. Joshi et al. (1970) used etching to document rhombohedral cleavage in quartz. In their later work, they describe the effect of dislocations on etch mark development on amethyst rhombs Joshi et al. (1978). Brantley et al. (1986) described in detail the influence of dislocations on the kinetics of surface dissolution. Our work aims to evaluate the (i) solubility of individual crystal faces of quartz and (ii) dissolution of the areas of mechanical defects in comparison with dissolution of perfect crystal faces, and utilization of this knowledge in the study of metasomatic quartz dissolution.

\section{METHODS OF STUDY}

Two methods of quartz etching and dissolution were applied: (1) autoclave temperature and pressure experiments of hydrothermal conditions of dissolution with distilled water, and (2) chemical etching of quartz with hydrofluoric acid.

A Parr instrument set was used to simulate hydrothermal P-T conditions. This set consists of a 4652 Parr reactor with a stainless vessel internal volume of $500 \mathrm{ml}$ allowing the study of macroscopic samples heated in a 4923 Heater. The temperature was set and kept constant with help of a 4842 Temperature controller. Pressure was controlled by the quantity of liquid in the reactor and the set temperature. A volume of $65 \mathrm{ml}$ of distilled water was used as a dissolving fluid in all the hydrothermal simulation experiments presented below. Each experiment was performed in a closed system during 7 days. Four groups of experiments were carried out (Table 1). The maximum P-T conditions which can be reached by this instrument set, are 340 bar and $500{ }^{\circ} \mathrm{C}$.

Table 1 Characteristics of the samples and the conditions of the experiments.

\begin{tabular}{|c|c|c|}
\hline Type of dissolution & Sample type & Dissolution conditions \\
\hline 1. Hydrothermal simulation & Complete quartz crystals & $\begin{array}{l}320-370{ }^{\circ} \mathrm{C} \\
120-230 \mathrm{bar}\end{array}$ \\
\hline 2. Hydrothermal simulation & $\begin{array}{l}\text { Complete quartz crystals with mechanically } \\
\text { disrupted crystal face }\end{array}$ & $\begin{array}{l}320-370{ }^{\circ} \mathrm{C} \\
120-230 \text { bar }\end{array}$ \\
\hline 3. Hydrothermal simulation & Quartz sphere cut from a crystal & $\begin{array}{l}320-370{ }^{\circ} \mathrm{C} \\
120-230 \text { bar }\end{array}$ \\
\hline 4. Hydrothermal simulation & $\begin{array}{l}\text { Plates parallel to crystal faces: } \\
\text { Prism: } \mathrm{P}_{1}, \mathrm{P}_{2}, \mathrm{P}_{3}, \mathrm{P}_{4} \\
\text { Rhomb: } \mathrm{R}_{1}, \mathrm{R}_{2}, \mathrm{R}_{3}, \mathrm{R}_{4}\end{array}$ & $\begin{array}{l}220^{\circ} \mathrm{C} \\
18-25 \text { bar }\end{array}$ \\
\hline 5. Chemical dissolution & $\begin{array}{l}\text { Plates parallel to crystal faces: } \\
\text { Prism: } \mathrm{P}_{5}, \mathrm{P}_{6}, \mathrm{P}_{7}, \mathrm{P}_{8} \\
\text { Rhomb: } \mathrm{R}_{5}, \mathrm{R}_{6}, \mathrm{R}_{7}, \mathrm{R}_{8}\end{array}$ & $\begin{array}{l}\text { Room temperature and } \\
\text { pressure }\end{array}$ \\
\hline
\end{tabular}


A summary of the experiments, samples and experimental conditions is presented in Table 1 . The quartz samples for these experiments have been obtained from commercial sources. Their origin, or locality, is not known. They were chosen because of highest quality natural (i.e. not polished) crystal faces.

From the 19 experiments, typical 5 examples documented by photos were selected for this publication. Complete quartz crystals $(1,2)$, a quartz sphere cut from a crystal (3) and thin quartz plates cut parallel to the crystal faces of prisms and rhombs (4) were used for the hydrothermal experiments (Fig. 2). The changes on the natural crystal face, which was kept on the plate surface, were studied after the experiment. The plates of about $1 \mathrm{~mm}$ thick were cut from a crystal using a diamond saw without further treatment. The crystal faces prior to etching were used as reference material.

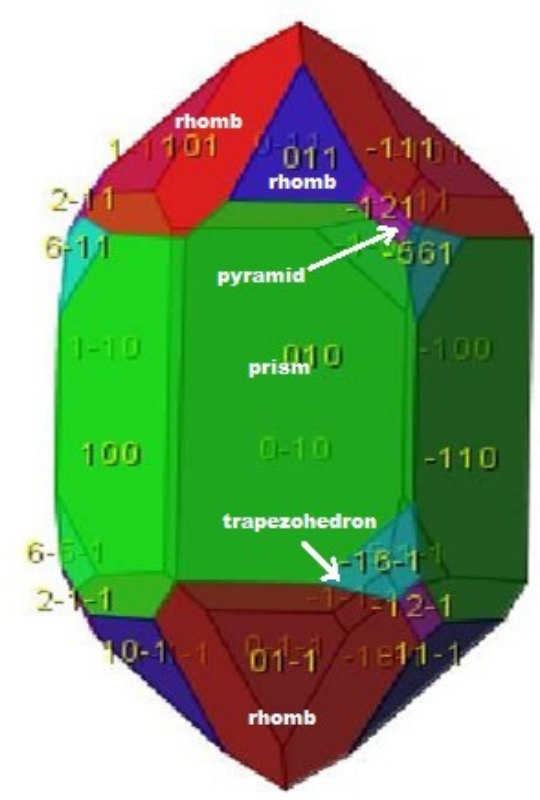

Fig. 2 Natural crystal planes of quartz. Adapted after

http://www.webmineral.com/data/Quartz.shtml

Experimental temperature and pressure were chosen as close as possible to the conditions of episyenitization $(1 ; 2 ; 3$; Table 1). As these experiments resulted in marked morphological changes on the surface of the samples, we carried out experiments with thin quartz plates (4) to compare the solubility of individual crystal faces. These experiments were performed at lower temperatures and pressures (Table 1) as a teflon insert had to be used to protect the walls of the reaction vessel during the experiment. During the $20-35$ minutes of cooling of the reactor (especially from the higher temperatures), $\mathrm{SiO}_{2}$ dissolved in the solution precipitated on its walls. The $\mathrm{SiO}_{2}$ film on the internal walls of the reactor could not be removed mechanically or chemically without damaging the vessel. The presence of the silica coating influenced all subsequent experiments, as it dissolved more easily than the quartz samples. The solution was therefore saturated by the $\mathrm{SiO}_{2}$ deposited on the walls earlier rather than by the $\mathrm{SiO}_{2}$ derived from the sample, which lowered the validity of each subsequent experiment. The use of the teflon insert allowed for the reaction space to be cleaned chemically and guaranteed the same initial conditions for each new experiment. This procedure however required the experimental temperature to be lowered as teflon only resists temperatures up to $250^{\circ} \mathrm{C}$.

The chemical dissolution of these plates using hydrofluoric acid (5) represented the last group of experiments. It should have served primarily as reference material. We aimed to compare the resulting etch marks and the intensity of dissolution from the hydrothermal and chemical process and to use the potential analogy to quantify the solubility of individual faces. The quartz plate dissolution was carried out in $10 \mathrm{ml}$ of $40 \%$ hydrofluoric acid at room temperature and pressure. Each experiment lasted 3.5 hours.

Weight of the quartz plates $(4 ; 5)$ was measured on laboratory scales before and after the experiment. Each pair of compared plates (rhomb/prism) was always made from one quartz crystal. Original weight of the plates varied between $0.19-0.26 \mathrm{~g}$. The weight difference/loss of particular plates was expressed in \% of original weight. The difference between weight losses of particular plates in pair prism/rhomb are described in chapter Experimental results.

The surfaces of the samples were studied by using a scanning electron microscope JEOL $6490 \mathrm{LV}$ (after gold-coating) in secondary electron imaging mode (SE) or using an electron microprobe Cameca SX 100 in back-scattered electron imaging mode (BSE).

\section{EXPERIMENTAL RESULTS}

Natural etches on quartz crystal faces were used as a standard reference material for evaluating the experimentally induced changes. The quartz surfaces in Figures 3 and 4 show corrosion as a result of natural dissolution from the Jinkohe locality in Ebian, Sichuan province, China. Individual crystal faces are characterized by a different character of dissolution and a different etching shapes. Prisms and rhombs represented the most numerous and best developed faces in this as well as other samples. Elongated striations, in some places elongated quadrangles or trapezoids or regular diamond shapes reaching in this case $10-40 \mu \mathrm{m}$ in size, are typical of prismatic faces (Fig. 3). By contrast, triangular etch shapes, in this case reaching $5-25 \mu \mathrm{m}$ in size, are characteristic of rhombs (Fig. 4). BSE images of crystal prisms (Fig. 5) and rhombs (Fig. 6) before experimental leaching are shown for comparison. Whereas the prismatic face shows no traces of dissolution, an initial stage of 


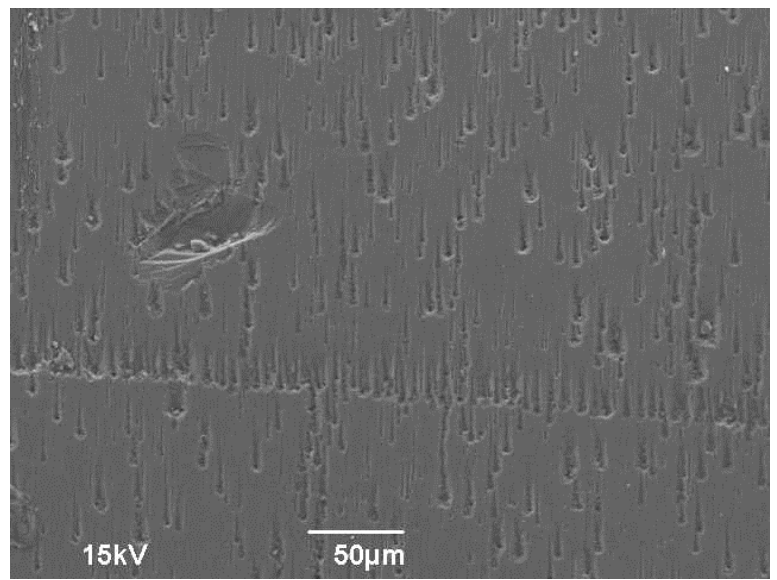

Fig. 3 Naturally dissolved prism. (SE)

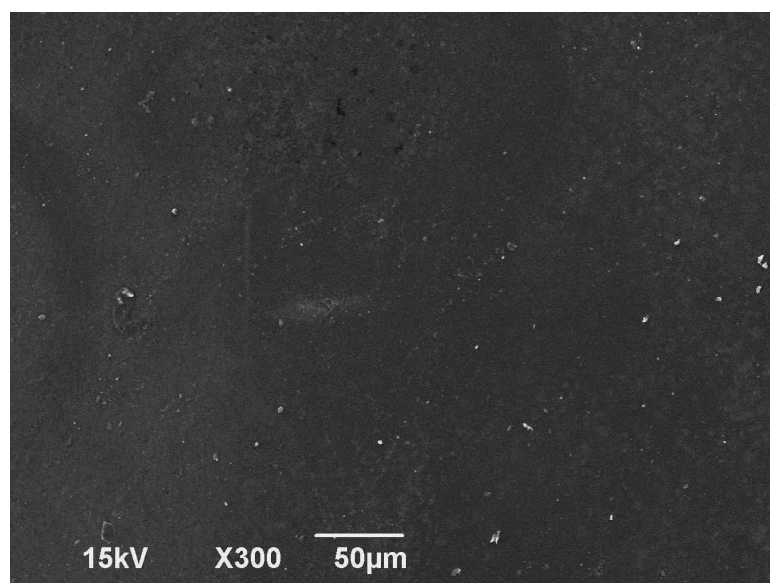

Fig. 5 Prism face before the experiment. (SE)

development of triangular etch pits can be observed on the rhomb surface.

\section{HYDROTHERMAL SIMULATION-COMPLETE QUARTZ CRYSTALS (Table 1)}

This first group of experiments was performed without attempting to compare the solubility of individual faces. The prism (Fig. 7) and rhomb (Fig. 8) faces show characteristic etch pits. The intensity of dissolution of the crystal faces is considerably higher compared to the natural etches (Figs. 3 and 4), and individual etch marks can no longer be distinguished. The prism face (Fig. 7) is no longer characterized by elongated quadrangles or discontinued striations, but by continuous striations, thus the size of individual etch marks cannot be determined. This is also the case of the rhombs, where triangular etch marks can be found, but these overlap so much that they cannot be individually determined and measured. The etch pits do not form closed triangles but overlapping arrows. It is however obvious that the dissolution at these highest simulated pressures and temperatures is more intensive and extensive compared to the experiments at lower temperatures and pressures.

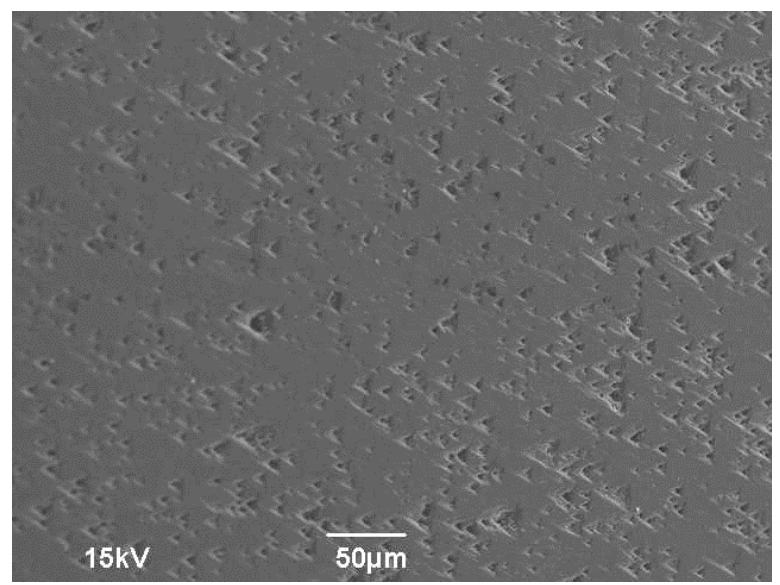

Fig. 4 Naturally dissolved rhomb. (SE)

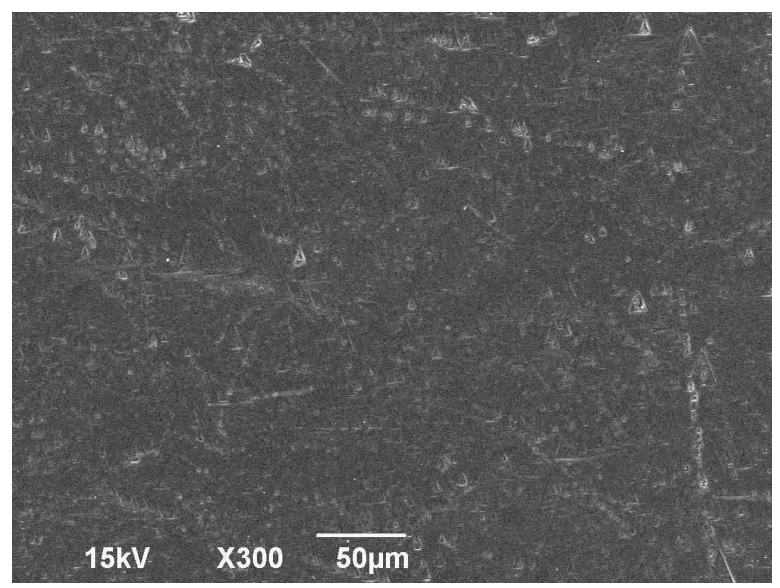

Fig. 6 Rhomb face before the experiment. (SE)

\section{HYDROTHERMAL SIMULATION-COMPLETE QUARTZ CRYSTALS WITH MECHANICALLY DISRUPTED CRYSTAL FACE (Table 1)}

Dissolution experiments using mechanically disrupted crystal faces were performed as part of the experimental dissolution of complete crystals. The prismatic face was disrupted by a diamond needle of about $120 \mu \mathrm{m}$ wide (Fig. 9). Results of the subsequent hydrothermal experiment show that dissolution of the mechanically disrupted area is significantly greater (Fig. 10). Comparison of the images acquired before and after the experiment reveal that the originally shallow scratch mark deepened considerably compared to the surrounding standard prismatic etches after the simulation of hydrothermal conditions. The mechanical disruption of the crystal surface significantly facilitates and determines further dissolution and its direction. Whereas the mean width of the mechanical defect remains unchanged, its depth increased by tens to hundreds of micrometers.

\section{HYDROTHERMAL SIMULATION-QUARTZ SPHERE CUT FROM A CRYSTAL (Table 1)}

A sphere made from a quartz crystal was used as a representative of natural quartz grains in rocks. It 


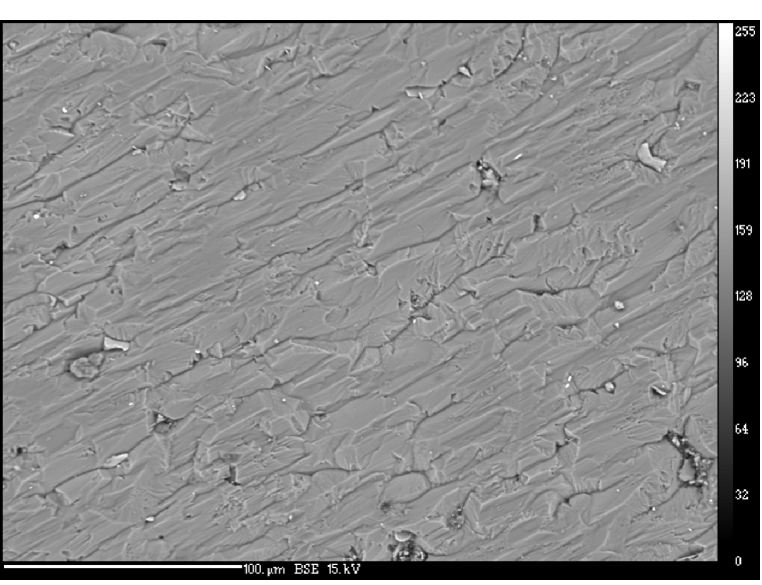

Fig. 7 Prism face. (BSE)

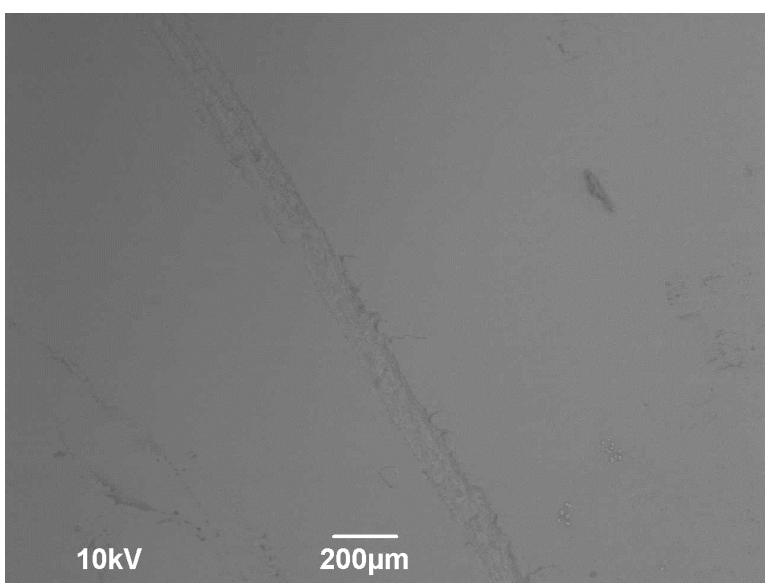

Fig. 9 Prism face with mechanically produced scratch mark before the experiment. (SE)

was also used to demonstrate that the internal symmetry of crystals shows up on the surface of a dissolved mineral although the crystal faces are not developed. It is commonly the case of mineral grains in natural rocks. Areas with different types of etches with contrasting symmetry and shape, corresponding to those characteristic of rhombs and prisms described above, developed on the originally smooth surface of the sphere (Fig. 11). These areas with a different etch symmetry featured both transitional and sharp boundaries (Fig. 12). Triangular etch marks reaching $30-50 \mu \mathrm{m}$ in size clearly corresponding to the shape of respective rhombs can be seen on the left in Figure 10. Elongated striations with deep diamondshaped etch marks that are characteristic of prisms, reaching $20-50 \mu \mathrm{m}$ in size, are shown on the right. The right part features a more intensive and extensive dissolution, whereas the left part is dominated by single but deep etch marks.

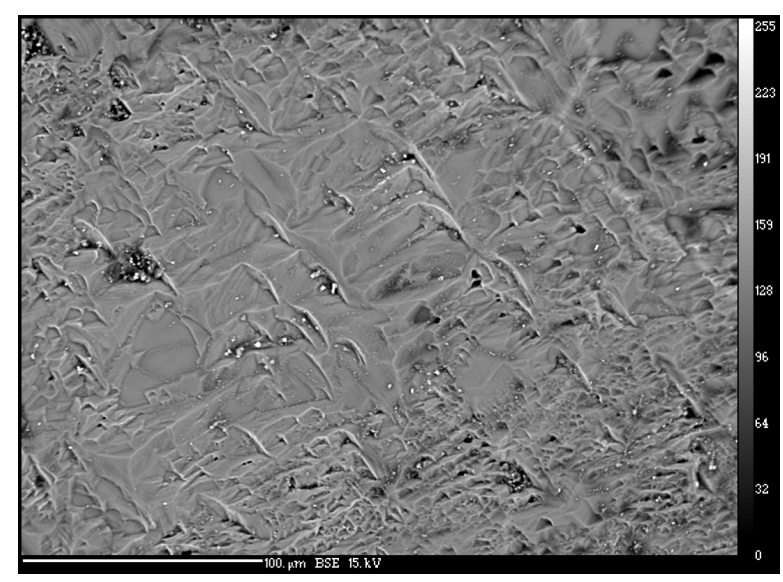

Fig. 8 Rhomb face. (BSE)

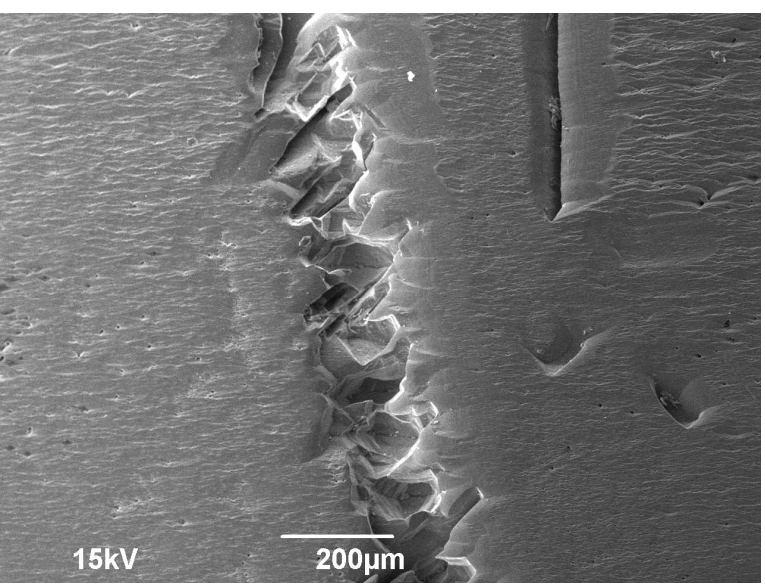

Fig. 10 Prism face with mechanically produced scratch mark after the experiment. (SE)

\section{HYDROTHERMAL EXPERIMENTS - QUARTZ PLATES PARALLEL TO CRYSTAL FACES (Table 1)}

This experimental series included four sets of samples. Each set consisted of one pair of plates cut parallel to the natural crystal face and included the surface of this natural crystal face. A plate parallel to the prism $\left(\mathrm{P}_{1}-\mathrm{P}_{4}\right)$ and a plate parallel to the rhomb $\left(\mathrm{R}_{1}\right.$ $R_{4}$ ) were represented in each pair. This series was used for comparing the solubility of individual crystal faces.

Elongated etches which are mostly continuous and form striations rather than separated etch forms develop on the prism face (Fig. 13). Their size is approximately $10-20 \mu \mathrm{m}$, but difficult to determine precisely. The diamond-shaped etch marks are shallow and incomplete, or deep, narrow and complete. Both the separated and overlapping triangular etch marks of various size ranging between 2 and $10 \mu \mathrm{m}$ can be clearly seen on the rhomb surface (Fig. 14). 


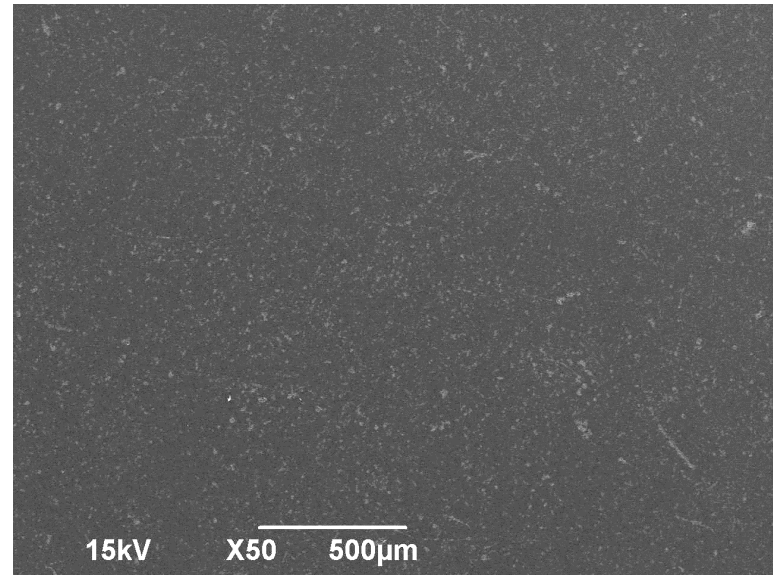

Fig. 11 Quartz sphere surface before the experiment. (SE)

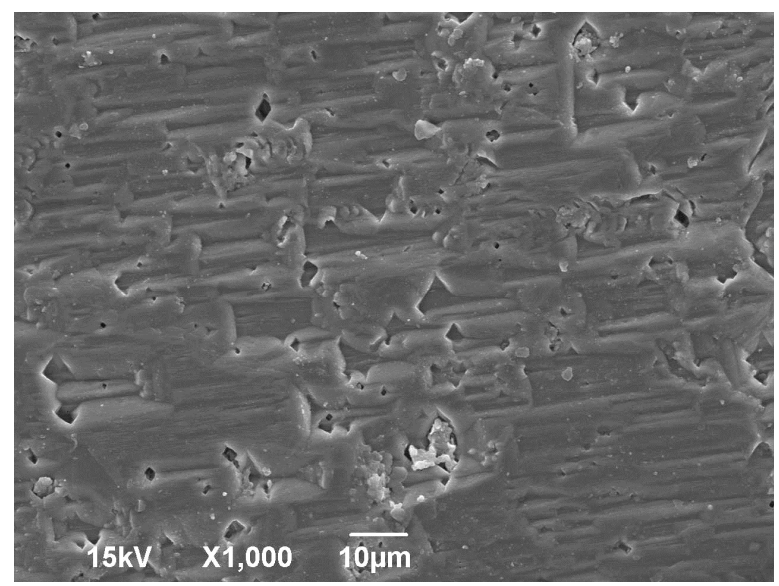

Fig. 13 Quartz plate parallel to the prism $\left(\mathrm{P}_{1}\right)$ after hydrothermal simulation. (SE)

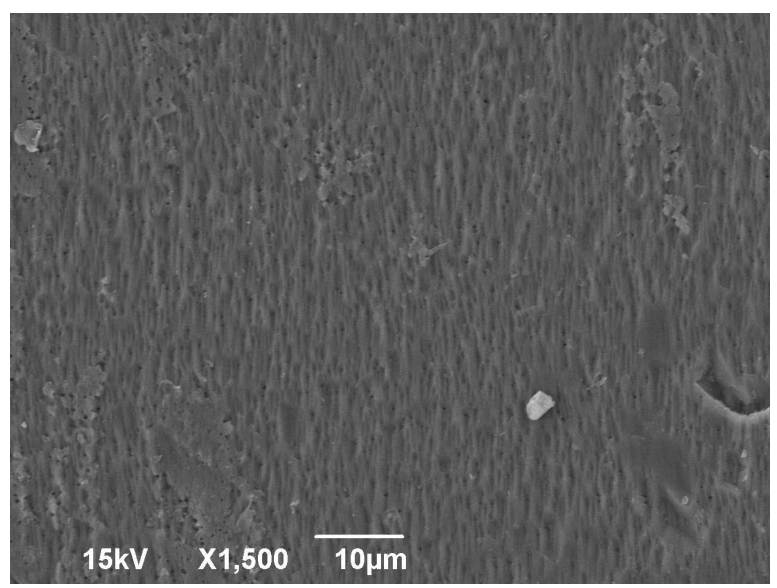

Fig. 15 Quartz plate parallel to the prism $\left(\mathrm{P}_{7}\right)$ after chemical dissolution in HF (SE)

All four experimental sets demonstrate a higher solubility of the quartz plates cut parallel to rhombs compared to those cut parallel to prisms. When expressed in percent, the solubility of rhombs is 0.20 $-1.4 \%$ higher than that of prisms.

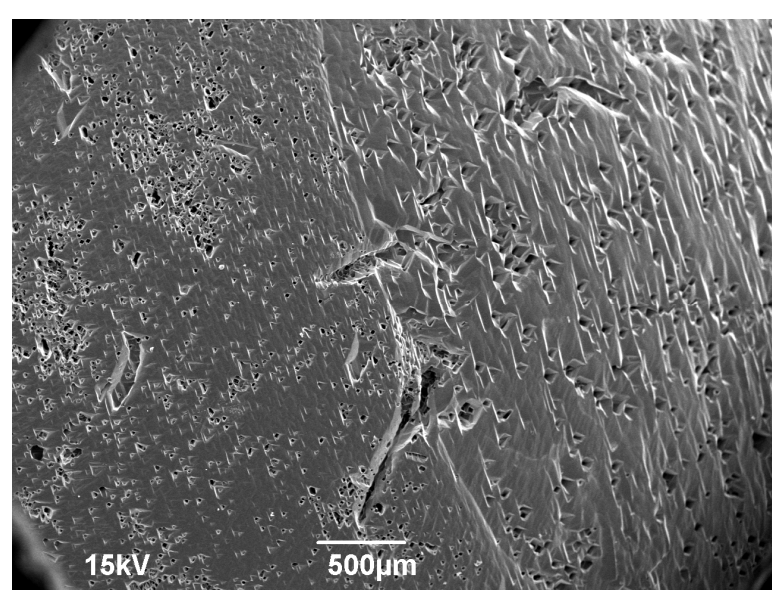

Fig. 12 Quartz sphere surface after the experiment. (SE)

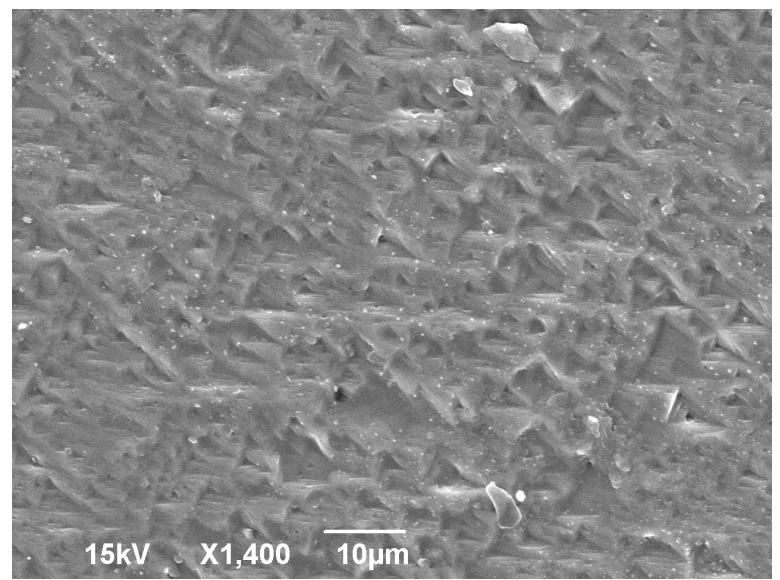

Fig. 14 Quartz plate parallel to the rhomb $\left(R_{1}\right)$ after hydrothermal simulation. (SE)

\section{CHEMICAL DISSOLUTION - PLATES PARALLEL TO CRYSTAL FACES (Table 1)}

This experimental series again included four sets of samples - four pairs of plates parallel to the prism (P5-P8) and rhomb (R5-R8). Hydrofluoric acid was used as a dissolving agent, as in the experiments described by Ježek (1932). We aimed to compare the solubility of individual faces, similar to the previous series of experiments, and to compare the results of this chemical dissolution with those from the hydrothermal simulations. Also in this case, the solubility of plates parallel to rhombs was always higher compared to the plates parallel to prisms. Expressed in percent - the solubility of rhombs is 1.2 to $1.8 \%$ higher.

Elongated striations rather than separated etch marks can be seen on the prism surface. They merge to such an extent that their size cannot be determined precisely. These striations are however noticeably finer than in the preceding cases. There are hardly any diamond-shaped etch marks (Fig. 15). Overlapping open triangular etch marks of variable size (again rather arrows than triangles) are clearly visible on the 


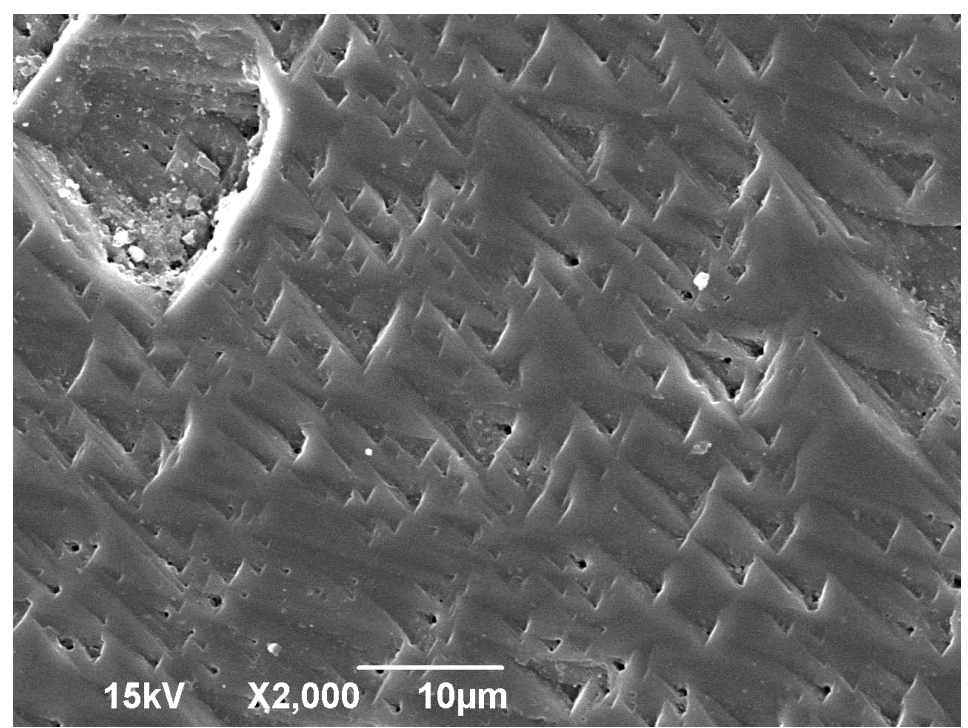

Fig. 16 Quartz plate parallel to the rhomb (R7) after chemical dissolution in HF (SE)

rhomb surface. The size of individual etch marks is difficult to determine, but ranges between 2 and $10 \mu \mathrm{m}$ (Fig. 16).

\section{DISCUSSION AND CONCLUSIONS}

Both the hydrothermal simulation experiments in a large volume temperature-pressure reactor and the chemical leaching experiments reveal that the quartz dissolution is anisotropic in relation to individual crystal faces and mechanical defects. Generally, the discussion of the experimental results can be separated in four subsections:

\section{Etch pits shapes}

The comparison of the etch pits of individual crystal faces of quartz clearly shows that the etching style of prisms is remarkably different than that of rhombs in both types of experiments. Elongated etch shapes or regular diamond etch shapes are typical for prismatic faces. By contrast, triangular etch shapes are characteristic of rhombs (Joshi et al., 1970). At lower temperatures and pressures (Table 1), etch marks of a similar shape could be observed both in the case of the naturally dissolved quartz surface from the Jinkohe locality and on the samples exposed to dissolution at higher temperature and pressure (quartz crystals and quartz sphere). The fact that rhombs are more susceptible to dissolution than prisms is also confirmed by the presence of initial triangular etch marks documented prior to etching when compared to the smooth face of a prism from the same crystal (Figs. 5 and 6). The experiments show that quartz dissolution by various fluids (distilled water and hydrofluoric acid) is similar for different pressures and temperatures.
2. Solubility and abundance of etch pits

The difference in the solubility of the two most common crystal faces of quartz mentioned above reaches relatively low values of $0.20-1.40 \%$ (Fig. 2; dissolution experiments using thin plates cut parallel to natural crystal faces). However, it has to be taken into account that the experiments were performed in a closed system and that the dissolution therefore always stopped when saturation was reached. This represents a significant difference from natural open systems. As shown by the hydrothermal experiments, the dissolution features and forms both at higher and lower temperature and pressure conditions are comparable (only the intensity, size and density of the etch pits increases with temperature). It is therefore probable that the trend observed in the experiments is even more significant for the conditions of natural quartz leaching. At lower temperatures the separated etch pits originate. With increasing temperature the etch pits start to link and we observe the continuous striations (prisms) or overlapping arrows (rhombs) without possibility of individual etch pits size determination. Although the solubility of rhombs is higher than that of prisms, Figures 8 and 12, for instance, show that the surface of prisms are more prone to extensive dissolution and that elongated etch marks easily merge into striations or channel forms, which may facilitate the migration of fluids more easily than the deep single triangular etch marks on rhombs. Based on the above mentioned experimental results, it is possible to presume similar behaviour of quartz grains in natural rocks. From this point of view two circumstances in natural rocks are important: a) an abundance of the dissolved grains and b) contact between the newly originated spaces is determining for the next fluid migration. The contrasting solubility 
of individual faces does not necessarily have a substantial impact on the whole metasomatic process, however, the relative abundance and size of these individual faces and their solubility probably represents an important factor determining potential fluid pathways through the rock. This also concerns material with undeveloped crystal faces, as shown by the experiment with the quartz sphere (Fig. 12) as a representative of mineral grains without crystal faces which are common in the nature.

\section{Influence of mechanical defects}

Fluid migration is still more influenced by mechanical defects on the crystal surface: our experiment using complete quartz crystal disrupted on the prism face by a diamond needle clearly showed, that such defects significantly enhance mineral solubility. The depth of the mechanical deffect increased from first tenmicrometers by tens to hundreds of micrometers after the experiment. (Fig. 10)

In this respect, brittle deformation commonly affecting quartz due to its lack of cleavage may play a decisive role in fluid migration through the rock. Defects of this type facilitate fluid migration, which is crucial in the episyenitization processes (Cathelineau, 1986; Hecht et al., 1999).

4. Synergy of three above mentioned anisotropic dissolution effect

The anisotropy of dissolution described above may have a particularly strong effect on rocks with a preferred orientation of mineral grains and rocks which were subject to brittle deformation. Anisotropic dissolution of quartz grains may represent another possible way for fluid migration through the rock, in addition to migration along cracks, cleavage and twinning planes in mineral grains described by Leichmann et al. (2003).

\section{REFERENCES}

Brantley, S.L., Crane, S.R., Crerar, D.A., Hellmann, R. and Stallard, R.: 1986, Dissolution at dislocation etch pits in quartz. Geochimica et Cosmochimica Acta, 50, 2349-2361, DOI: 10.1016/0016-7037(86)90087-6

Cathelineau, M.: 1986, The alkali metasomatism effects on granitic rocks: Quartz dissolution and related subsolidus Changes. Journal of Petrology, 27, 945965. DOI: $10.1093 /$ petrology/27.4.945

Dolejš, D. and Wagner, T.: 2008, Thermodynamic modeling of non-ideal mineral-fluid equilibria in the system $\mathrm{Si}-$ $\mathrm{Al}-\mathrm{Fe}-\mathrm{Mg}-\mathrm{Ca}-\mathrm{Na}-\mathrm{K}-\mathrm{H}-\mathrm{O}-\mathrm{Cl}$ at elevated temperatures and pressures: Implications for hydrothermal mass transfer in granitic rocks. Geochimica et Cosmochimica Acta, 72, 526-553. DOI: 10.1016/j.gca.2007.10.022

Gratz, A.J., Bird, P. and Quiro, G.B.: 1990, Dissolution of quartz in aqueous basic solution, $106-236^{\circ} \mathrm{C}$ : Surface kinetics of "perfect" crystallographic faces. Geochimica at Cosmochimica Acta, 54, 2911-2922. DOI: $10.1016 / 0016-7037(90) 90109-X$
Gratz, A.J. and Christie, J.M.: 1993, Recrystallization at grain contacts in a sandy siltstone. Journal of Structural Geology, 15, 1139-1144. DOI: 10.1016/0191-8141(93)90160-C

Hecht, L., Thuro, K., Plinninger, R. and Cuney, M.: 1999 , Mineralogical and geochemical characteristics of hydrothermal alteration and episyenitization in the Königshain granites, northern Bohemia Massif, Germany. Journ Earth Sciences, 88, 236-252. DOI: $10.1007 / \mathrm{s} 005310050262$

Ježek, B.: 1932, Mineralogy. Publishing house and bookstore of Czechoslovakia teachers in Prague, Ltd., 294-302, (in Czech).

Joshi, M.S., Kotru, P.N. and Ittiakhe, M.A.: 1970, Studying dislocations in quartz by hydrothermal - etching method. Soviet physics crystallography, USSR, 15, 103-111.

Joshi, M.S., Kotru, P.N. and Ittiakhe, M.A.: 1978, Revelation of stepped dislocations in amethyst crystals by hydrothermal etching. American Mineralogist, 63, 744-746.

Kříbek, B. and Hájek, A. eds., 2005: The Rozna uranium deposit. Model of the late Variscan and post Variscan mineralizations. 98 pp. Czech Geological Survey. Prague, (in Czech).

Kř́bek, B., Žák, K., Dobeš, P., Leichmann, J., Pudilová, M. and René, M.: 2009, The Rozna uranium deposit (Bohemian Massif, Czech Republic): shear zonehosted, late Variscan and post-Variscan hydrothermal mineralization. Mineralium Deposita, 10, 99-128.

Lasaga, A.C. and Blum, A.E.: 1986, Surface-chemistry, etch pits and mineral-water reactions. Geochimica at Cosmochimica Acta, 50, 2363-2379.

DOI: 10.1016/0016-7037(86)90088-8

Leichmann, J., Broska. I. and Zachovalová, K.: 2003, Lowgrade metamorphic alteration of feldspar minerals: a CL study. Terra Nova, 15, 104-108. DOI: $10.1046 / \mathrm{j} .1365-3121.2003 .00467$

Liang, D.-T. and Readey, D.W.: 1987, Dissolution kinetics of crystalline and amorphous silica in hydrofluorichydrochloric acid mixtures. Journal of American Ceramic Society, 70, 570-577.

DOI: $10.1111 / j .1151-2916.1987 . t b 05708 . x$

Petersson, J. and Eliasson, T.: 1997, Mineral evolution and element mobility during episyenitizationion (dequartzification) and albitization in the postkinematic Bohus granite, southwest Sweden. Lithos, 42, 123-146. DOI: $10.1016 / 5024-4937(97) 00040-6$

Petersson, J., Stephens, H.-B., Mattsson, H. and Möller, Ch.: 2012, Albitization and quartz dissolution in Paleoproterozoic metagranite, central Sweden Implications for the disposal of spent nuclear fuel in a deep geological repository. Lithos, 148, 10-26. DOI: $10.1016 /$ j.lithos.2012.06.001

Pielow, H.-U.: 1998, Albitisierte Plagioklase, korrodierte Quarze und die Genese von Basement Brines. Freiberger Forschungshefte, Hefte C 475, 85-94.

Shmulovich, K.I., Graham, C.M. and Yardley, B.W.D.: 2001, Quartz, albite and diopside solubilities in $\mathrm{H}_{2} \mathrm{O}-$ $\mathrm{NaCl}$ and $\mathrm{H}_{2} \mathrm{O}-\mathrm{CO}_{2}$ fluids at 0.5-0.9 GPa. Contrib Minaral Petrol, 141, 95-108. http://www.webmineral.com/data/Quartz.shtml 